\title{
Plantas medicinais abortivas utilizadas por mulheres de UBS: etnofarmacologia e análises cromatográficas por CCD e CLAE
}

SOUZA MARIA, N.C.V. ${ }^{1}$; TANGERINA, M.M.P. ${ }^{2}$, SILVA, V.C...2; VILEGAS, W. ${ }^{2}$; SANNOMIYA, M. ${ }^{1 *}$

${ }^{1}$ Universidade de São Paulo, Escola de Artes, Ciências e Humanidades, Rua Arlindo Bettio, 1000, Bairro Ermelino Matarazzo, CEP: 3828-000, São Paulo-Brasil *miriamsan@usp.br ${ }^{2}$ Universidade Estadual Paulista "Júlio de Mesquita Filho", Instituto de Química, Departamento de Química Orgânica, Rua Francisco Degni, s/n, Bairro Quitandinha, CEP: 14800-900, Araraquara-Brasil

RESUMO: O emprego de plantas medicinais refere-se a uma prática milenar, seja na medicina alternativa para cura de diversas doenças, ou como método abortivo. No entanto, a população em geral desconhece os grandes riscos que a cometem. Neste sentido este trabalho teve como objetivo avaliar o índice de consumo de plantas medicinais por mulheres de uma Unidade Básica de Saúde (UBS), na tentativa de identificar quais as espécies mais frequentemente ingeridas inclusive em período gestacional. Através de um questionário de caráter explorativo com 48 mulheres observou-se que a maioria das entrevistadas tinha filhos e as plantas medicinais mais citadas foram "boldo" (Peumus boldus), "carqueja" (Baccharis trimera) e "sene" (Cassia angustifolia), as quais eram empregadas principalmente em dores estomacais ou como digestivos $(53 \%)$, para resfriados $(23 \%)$, cólicas menstruais $(4 \%)$ ou para menstruar $(2 \%)$. Outra parte do trabalho constituiu a análise visual e química de espécies de plantas medicinais citadas pelo público feminino entrevistado, bem como, outras utilizadas popularmente com propriedades abortivas. Análises visuais comparativas de amostras de plantas medicinais de quatro estabelecimentos comerciais diferentes denominadas Grupo A-C, mostraram a ausência de controle de qualidade com relação às especificações nas embalagens, e separação do material vegetal a ser consumido. Através de análises dos perfis químicos destas amostras por cromatografia em camada delgada (CCD) e cromatografia líquida de alta eficiência (CLAE) indicaram que aquelas pertencentes ao Grupo $C$ diferiram significativamente em relação àquelas de mesma identificação, exceto no que se refere ao boldo do Chile, cujas amostras apresentaram-se bastante similares com relação à constituição química.

Palavras-chave: mulheres, UBS, plantas medicinais, abortivas

ABSTRACT: AAbortive medicinal plants used by women of Basic Health Units: ethnopharmacology and cromatographic analysis by TLC and HPLC. The use of medicinal plants corresponds to an ancient practice, either as an alternative medicine for the cure of several diseases, or as a method of abortion. Nevertheless, the population in general does not know the risks involved in the use of medicinal plants. In this sense, the purpose of the study was to evaluate the consumption rate of medicinal plants by women in a Basic Health Unit (BHU), on order to identify which plant species have been most frequently consumed by them, including during the pregnancy. Through an exploratory questionnaire with 48 women, it was observed that most part of the interviewees had children and the most of them cited Peumus boldus, Baccharis trimera and Cassia angustifolia, which were mainly used for stomach aches or digestives (53\%), for colds (23\%), menstrual cramps $(4 \%)$ or to menstruate $(2 \%)$. The remaining part of the study consisted in the visual and chemical analysis of the plant species cited by the interviewees, including other species that have been popularly used as a method of abortion. Comparative visual analysis of medicinal plants (Group A-C) from four different shops showed the absence of quality control concerning packing specifications and the separation of the plant material to be consumed. The analysis of the chemical profiles of these samples by thin layer chromatography (TLC) and high performance liquid chromatography (HPLC) indicated that those species belonging to the Group $\mathrm{C}$ were significantly different from those plants having the same identification, except for Peumus boldus, whose samples were similar in terms of chemical composition.

Keywords: women, medicinal plants, abortive plants 


\section{INTRODUÇÃO}

As plantas medicinais desde os mais remotos tempos fazem parte do cenário mundial. Cerca de três quartos da população depende principalmente de plantas medicinais ou extratos vegetais para os mais variados males (TEEB, 2010).

No Brasil é constatado que $63 \%$ dos brasileiros fazem uso de medicamentos disponíveis no mercado, e o restante procura nos produtos de origem natural, especialmente nas plantas medicinais, a única fonte de recurso terapêutico (Di Stasi, 1996). A importância econômica das plantas medicinais é mais contundente em países menos desenvolvidos, apesar de se observar a crescente procura por extratos vegetais ou plantas medicinais inclusive por países como EUA, Reino Unido e Alemanha. Este aumento se deve à acessibilidade, disponibilidade, histórico, conhecimento popular e crenças na ausência de toxicidade ou efeitos colaterais destes produtos (Haq, 2004).

Estimativas mundiais indicam que $80 \%$ da população mundial não tem acesso aos medicamentos oriundos de indústrias farmacêuticas e lançam mão de medicamentos tradicionais, principalmente aqueles derivados de plantas (Farnsworth et al., 1985).

É apreciável a tendência mundial para o consumo de plantas medicinais, seja advindo do incentivo da mídia, apelo proveniente de naturalistas para o uso destas plantas como medicina alternativa, ou ainda como método preventivo. Neste sentido é importante salientar que ainda é precário o controle de qualidade, coleta, classificação botânica e forma de processamento e armazenamento de fitoterápicos disponíveis no mercado mundial. Cerca de $50 \%$ dos fitoterápicos brasileiros apresentam alguma forma de irregularidade, seja pela presença de impurezas, problemas de identificação botânica, teores de fitocompostos abaixo do esperado ou adulteração (Reis et al., 2002). A presença de impurezas, ocorrência de adulterações ou escassez de estudos de toxicidade em fitoterápicos pode acarretar em eventos indesejados como o aborto (Rodrigues et al., 2011).

A Organização Mundial da Saúde (OMS) define aborto como a morte ou expulsão do concepto antes da $22^{\mathrm{a}}$ à $28^{\mathrm{a}}$ semana de gravidez, podendo ser classificado como espontâneo e induzido (Bakke et al., 2008). Globalmente, mais de 500.000 mulheres morrem todos os anos de causas relacionadas com a gravidez. Apesar do intenso uso da contracepção, nas últimas três décadas, estima-se que ocorra, anualmente, 40 a 50 milhões de abortos (WHO, 2003).

A real magnitude do abortamento, no mundo, é desconhecida, pois a ilegalidade, parcial ou total em diversos países, dificulta o registro de todas as ocorrências. A prática do aborto induzido é legalizada em países como EUA, Inglaterra e China (Santos, 1993). De acordo com o código Penal Brasileiro, em nosso país, o aborto é considerado crime, com punição para aqueles que atentem contra a vida do embrião, com penas que vão de 01 (um) a 3 (três) anos de detenção à gestante (Código Penal, Artigos 124-128, Decreto Lei n ${ }^{\circ} 2848$ de 7 de Dezembro de 1940). No entanto, muitas mulheres recorrem a métodos clandestinos para abortar, pondo em risco a própria vida (Bakke et al., 2008).

Existem vários fatores que podem levar as mulheres à prática do aborto, como fragilidade psicológica e medo da desonra. Sem dúvida o aborto é mais procurado em situações em que a gravidez não é desejada, situações nas quais mulheres não entendem que o aborto é de fato um crime e adotam esta medida acreditando que estão corrigindo um erro (Santos, 1993). Dentre os métodos mais procurados para esta prática estão métodos cirúrgicos, uso de medicamentos como o Misoprostol (Cytotec $($ ) ou ainda, chás e infusões de plantas medicinais (Moreira et al., 2001; Mengue et al., $1998 \mathrm{~b}$ ).

Existem muitas plantas que são utilizadas pela medicina popular brasileira como abortivas. Dentre estas, destacam-se as espécies de Ruta graveolens L. (arruda), Salvia officinalis L. (sálvia), Punica gravatum L. (romã), Datura suaveolens Willd. (beladona), Allium sativum L. (alho), Aloe ferox Miller. (aloe), Angelica archangelica L. (angélica), Arnica montana L. (arnica), Cinnamomum canphora L. (cânfora), Symphitum officinale L. (confrei), Eucaliptus globulus Labill. (eucalipto), Rosmarinus officinalis L. (alecrim), Zingiber officinalis (Willd.) Roscoe. (gengibre), Cassia angustifolia M. Vahl., C. acutifolia (Delile) Batka (sene), Hibiscus rosasinensis L. (hibiscus), Baccharis genistelloides Pers. ou B. trimera (Less.) DC. (carqueja), Peumus boldus Molina (boldo), Luffa operculata Cogn. (buchinha do norte), Artemisia vulgaris L. (Artemísia), Hibiscus sabdariffa L. (hisbiscus) (Moreira, 2001; Basu, 1946; Suttisri, 1994; Mengue et al., 1997; Veiga Jr., 2005; Nácul et al., 2001; Frimpong, 2008).

O emprego de plantas medicinais como método abortivo torna-se uma prática baseada na cultura popular, desprovida de qualquer tipo de conhecimento a respeito de possível toxicidade, mutagenicidade ou efeito teratogênico de muitos compostos presentes em plantas. A falta de conhecimento da toxicidade de espécies utilizadas habitualmente pode levar à consequências sérias, já que algumas espécies podem apresentar algum tipo de efeito lesivo ou substâncias nocivas, causando distúrbios ao organismo pelo contato ou ingestão. Se utilizadas durante a gravidez, podem ser fatais, 
levando à morte da mãe e do feto (Oliveira \& Gonçalves, 2006; Silva et al., 2010). Este é o caso da espinheira-santa (Maytenus ilicifolia), utilizada popularmente em disfunções gástricas, porém apresentou efeito abortivo em ratas grávidas (Montanari et al., 2002). Assim, é imprescindível um melhor conhecimento a cerca do bom uso e dos riscos que as plantas podem apresentar.

Neste sentido, são imprescindíveis estudos abordando plantas medicinais seja para uma investigação da constituição química, a confirmação das atividades farmacológicas e averiguação de possíveis efeitos colaterais, ou estudos que forneçam subsídios para melhor controle de qualidade destas em nosso país. Assim o objetivo deste trabalho foi identificar e avaliar o índice de consumo e identificação de quais as plantas medicinais mais utilizadas por mulheres entrevistas de uma Unidade Básica de Saúde (UBS) de São Paulo, inclusive em período gestacional e a analisar visualmente e quimicamente algumas amostras de plantas medicinais adquiridas em diferentes estabelecimentos comerciais, as quais possuem como efeito colateral a propriedade abortiva.

\section{MATERIAL}

\section{Metódo}

A pesquisa foi realizada no Hospital Maternidade Engenheiro Trindade, situada na região da Zona Leste da cidade de São Paulo. A coleta de dados foi feita em 10 de junho de 2010 e se deu em quatro etapas:

Primeira etapa: em reunião com a direção do Hospital Maternidade Engenheiro Trindade, foi apresentada a intenção da pesquisa às mulheres que frequentam o mesmo para identificação do possível consumo de plantas medicinais e bem como a finalidade pela qual estas eram utilizadas.

Segunda etapa: mulheres dispostas a participar da pesquisa foram identificadas e cadastradas pessoalmente através do preenchimento de um termo de consentimento, e de um questionário de caráter exploratório qualitativo a fim de identificar quais eram as espécies de plantas utilizadas, forma de utilização (preparo, dosagem e administração) e a finalidade do uso.

Terceira etapa: no mês de agosto de 2010, amostras das plantas citadas pelas mulheres entrevistadas e outras utilizadas popularmente para fins abortivos, foram compradas em quatro estabelecimentos diferentes sendo três delas adquiridas na cidade de Mogi das Cruzes- SP, e outra em Itapecerica da Serra- SP.

Quarta-etapa: Os perfis químicos das amostras das plantas obtidas no comercio de
Mogi das Cruzes e Itapecerica da Serra foram obtidos através de análises por cromatografia em camada delgada analítica (CCD) e revelação com reveladores específicos para diferentes classes de produtos naturais como anisaldeído (universal), NP/ PEG (flavonóides), UV visível (compostos contendo grupos cromóforos), dragendorff (alcalóides) e iodo platinado (universal).

Para atribuição do local onde seria realizada a pesquisa, inicialmente optou-se por uma Unidade Básica de Saúde (UBS) que se localizasse na região da Zona Leste de São Paulo. Assim, optou-se a realização da pesquisa através de questionário contendo sete perguntas junto à UBS Engenheiro Trindade (Zona Leste -SP).

Para a elaboração do questionário aplicado em mulheres da UBS Engenheiro Trindade optouse por questões nas quais não se mencionava a terminologia "aborto ou plantas medicinais abortivas" para evitar a indução das respostas e a grande problemática social que permeia este assunto em nosso país.

A escolha das mulheres a participar do projeto em questão foi de modo aleatório, sendo restringidas somente àquelas que se encontravam na área ginecológica desta UBS. Foram entrevistadas 48 mulheres com faixa etária de 17 a 73 anos, das quais $78 \%$ possuem filhos.

\section{Material vegetal}

Com base no resultado obtido a partir do questionário aplicado a 48 mulheres que frequentam a UBS Engenheiro Trindade, bem como, outras espécies conhecidas pelo uso popular como abortivas, foram selecionadas "sene" (Cassia angustifolia), "boldo do Chile" (Peumus boldus), "carqueja" (Baccharis trimera), "buchinha do norte" (cc), "artemísia" (Artemisia vulgaris) e "hibiscus" (Hisbiscus sabdariffa).

O material vegetal foi adquirido em quatro estabelecimentos diferentes, sendo três na cidade de Mogi das Cruzes-SP e um, em feira livre de Itapecerica da Serra-SP.

As amostras foram divididas em quatro grupos denominados $\boldsymbol{A}, \boldsymbol{B}, \boldsymbol{C}$ e $\boldsymbol{D}$. As amostras presentes no Grupo A foram $H$. sabdariffa, $C$. angustifolia, $P$. boldus e $B$. trimera. Já as do Grupo $B$ foram adquiridas no Mercado Municipal de Mogi das Cruzes ( $A$. vulgaris, $C$. angustifolia, $P$. boldus, $B$. trimera e $L$. operculata). No mesmo Mercado Municipal, porém em outro estabelecimento, foram adquiridas as amostras do Grupo $C, H$. sabdariffa, C. angustifolia, P. boldus e B. trimera. As amostras oriundas de Itapecerica da Serra, denominadas Grupo $D$ foram compradas em feira livre sendo $H$. sabdariffa, $C$. angustifolia, B. trimera, $P$. boldus e $L$. operculata (Tabela 1). 
TABELA 1. Plantas medicinais mencionadas no questionário aplicado às mulheres da UBS e outras utilizadas popularmente com finalidades abortivas.

\begin{tabular}{cccc}
\hline & \multicolumn{2}{c}{ Plantas medicinais } & \\
\hline Grupo A & Grupo B & Grupo C & Grupo D \\
\hline Hisbiscus sabdariffa & - & Hisbiscus sabdariffa & Hisbiscus sabdariffa \\
Cassia angustifolia & Cassia angustifolia & Cassia angustifolia & Cassia angustifolia \\
Peumus boldus & Peumus boldus & Peumus boldus & Peumus boldus \\
Baccharis trimera & Baccharis trimera & Baccharis trimera & Baccharis trimera \\
- & Luffa operculata & - & Luffa operculata \\
- & Artemisia vulgaris & - & - \\
\hline
\end{tabular}

\section{Obtenção dos extratos vegetais}

Dois gramas $(\mathrm{g})$ de cada amostra foram pesados em balança analítica e inseridos individualmente em erlenmeyers de $125 \mathrm{~mL}$. Ao material foi adicionado inicialmente $50 \mathrm{~mL}$ de etanol até completa imersão. O processo de extração se deu por agitação mecânica durante um período de 15 min (3x). O extrato foi filtrado em algodão, obtendo o filtrado. Para garantir melhor extração dos constituintes químicos, adicionou-se em seguida sobre cada amostra, o volume de $25 \mathrm{~mL}$ de etanol.

\section{Análises cromatográficas por cromatografia de alta performance (CLAE) \\ $O$ equipamento utilizado foi cromatógrafo} analítico gradiente quaternário, Modelo PU-289 $\left(\right.$ Jasco $\left.^{\circledR}\right)$, acoplado a detector de arranjo de fotodiodos, modelo MD_2010 (Jasco®) e injetor automático modelo AS-2055 (Jasco®).

Para obtenção dos perfis químicos das amostras de plantas medicinais estudadas neste trabalho foram injetas em coluna Phenomenex Luna C18 (2) $5 \mu, 250 \times 4,60 \mathrm{~mm}$ e pré-coluna Phenomenex SecurityGuard C18 4 × 3,0 mm.

A fase móvel utilizada foi de modo gradiente exploratório com 5-100\% MeOH+0,1 TFA em 60 min.

\section{RESULTADO E DISCUSSÃO}

Dentre as participantes $75 \%$ alegaram fazer uso de plantas medicinais. Um percentual de $74 \%$ das entrevistadas indicou a obtenção destas plantas medicinais através de cultivo próprio, $16 \%$ adquirem em feiras livres ou raizeiros e $10 \%$ compram em farmácias de manipulação. A grande maioria das mulheres (74\%) afirmou obter o conhecimento das propriedades medicinais das plantas empregadas através de familiares e amigos, enquanto $23 \%$ obtiveram a informação em livros. As plantas medicinais com propriedades mais consumidas e citadas pelas entrevistas são boldo (42\%), carqueja $(19 \%)$, sene (24\%), arruda (2\%), camomila ( $8 \%)$ e outras (3\%). Os dados indicaram que as plantas medicinais citadas são principalmente utilizadas para amenizar dores estomacais ou como digestivos (53\%), para resfriados (23\%), cólicas $(4 \%)$ ou para menstruar $(2 \%)$.

A grande maioria relatou usar basicamente as folhas destas plantas com modo de preparo na forma de decocção $(75 \%)$ e $21 \%$ na forma de chá. No entanto, $24 \%$ das mulheres usavam tanto as folhas como os galhos. Dentre as entrevistadas $20 \%$ utilizavam as três plantas medicinais ( $P$. boldus, $C$. angustifolia e $B$. trimera) mesmo sendo gestantes, confirmando o uso indiscriminado de plantas medicinais baseadas na crença de que as mesmas não fazem mal à saúde. E principalmente, desconhecendo as ações abortivas.

A partir do questionário foi possível atribuir que carqueja, boldo do Chile e sene foram as plantas medicinais mais citadas nas entrevistas, mesmo em período gestacional. Adicionalmente foram incluídas $H$. sabdariffa, $A$. vulgaris e $L$. operculata como espécies abortivas para realização das análises químicas. Assim sendo, outra parte do trabalho consistiu na avaliação do perfil químico de diferentes fontes comercializáveis de $B$. trimera, $P$. boldus, $C$. angustifolia, $H$. sabdariffa, $A$. vulgaris e $L$. operculata, as quais são popularmente empregadas por mulheres para provocar o aborto. De acordo com a literatura, todas estas espécies possuem propriedades abortivas confirmadas, fato é que a venda de buchinha do norte é proibida, no entanto é possível adquirir o material vegetal em alguns estabelecimentos, porém não de forma expositiva.

Foram adquiridas plantas medicinais de 4 estabelecimentos diferentes disponíveis no comércio de Mogi das Cruzes-SP e Itapecerica da Serra- SP, as quais foram reunidas em Grupos de $A-D$ (Tabela 1). De acordo com a Tabela 2, observase que as plantas medicinais disponíveis nestes estabelecimentos não exibem controle de qualidade e/ou padronização para o consumo das mesmas. Dentre os grupos de plantas medicinais analisados, $A$ e $D$ apresentam rotulação contendo o nome científico da planta, o peso líquido, valor nutricional, identificação do farmacêutico responsável e bem como data de fabricação e validade. No caso dos Grupos B e $C$ encontram-se somente descritos o nome popular e a data de validade. No caso específico do boldo do Grupo B, a validade encontrase indevidamente apresentada (07/20/2011). Com

Rev. Bras. PI. Med., Campinas, v.15, n.4, supl.I, p.763-773, 2013. 
relação ao peso líquido na embalagem, somente as plantas dos Grupos A e $D$ apresentam sua menção $(30 \mathrm{~g})$. No entanto, apesar daquelas presentes no Grupo $A$ terem embalagem diferenciada, mais apresentável ao consumidor, e serem mais caras do que as demais, todas as amostras apresentaram peso líquido maior do que aquele mencionado na embalagem (Tabela 2).

Comparativamente foi possível observar uma variação de até 2,00 reais no custo de cada material vegetal como é o caso da carqueja, dependendo da fonte comercializável.

Através da análise visual das características físicas do material vegetal adquirido, observase claramente um melhor controle de qualidade nas amostras do Grupo $A$, enquanto nos demais existe mistura considerável de diferentes partes das plantas. Sabe-se que a composição química e consequentemente o potencial farmacológico de um fitoterápico ou planta medicinal, é totalmente dependente da parte da planta que se usa. Portanto, a mistura de diferentes partes do material vegetal infere significativamente no seu potencial ou atividade biológica.

Através das análises químicas dos perfis cromatográficos em CCD, utilizando como fase móvel a mistura de $\mathrm{CHCl}_{3} 100 \%$ e $\mathrm{CHCl}_{3} / \mathrm{MeOH} /$ $\mathrm{H}_{2} \mathrm{O}$ nas proporções 80:18:2, v/v (fase inferior) de todos os Grupos de $A-D$, observou-se que as substâncias presentes no Grupo C, com exceção de sene, diferem consideravelmente com relação aos constituintes químicos presentes nas demais

TABELA 2: Características e informações disponíveis nas embalagens das plantas medicinais adquiridas no comércio de Mogi das Cruzes e Itapecerica da Serra.

\begin{tabular}{|c|c|c|c|c|c|c|}
\hline \multicolumn{7}{|c|}{ Grupo A } \\
\hline Planta medicinal & Características & $\begin{array}{c}\text { Data da } \\
\text { embalagem }\end{array}$ & $\begin{array}{c}\text { Data de } \\
\text { validade }\end{array}$ & $\begin{array}{l}\text { Preço } \\
\text { (reais) }\end{array}$ & $\begin{array}{c}\text { Peso } \\
\text { Líquido (g) }\end{array}$ & $\begin{array}{c}\text { Peso } \\
\text { Observado (g) }\end{array}$ \\
\hline Hibiscus sabdariffa (flor) & Flor seca com coloração vinho & $04 / 2010$ & $04 / 2012$ & 6,00 & 30 & 43,4 \\
\hline $\begin{array}{c}\text { Cassia angustifolia } \\
\text { (folhas) }\end{array}$ & $\begin{array}{c}\text { Mistura de folhas amarelas e } \\
\text { verdes }\end{array}$ & 04/2010 & 04/2012 & 2,70 & 30 & 42,6 \\
\hline Peumus boldus (folhas) & Folhas verdes secas e galhos & $04 / 2010$ & $04 / 2012$ & 2,50 & 30 & 32,2 \\
\hline $\begin{array}{c}\text { Baccharis trimera (planta } \\
\text { inteira) }\end{array}$ & $\begin{array}{l}\text { Folhas e galhos com } \\
\text { coloração verde escuros }\end{array}$ & $04 / 2010$ & $04 / 2012$ & 3,00 & 30 & 52,1 \\
\hline \multicolumn{7}{|c|}{ Grupo B } \\
\hline Artemisia vulgaris & $\begin{array}{l}\text { Folhas e galhos e mistura de } \\
\text { outras plantas }\end{array}$ & - & $29 / 08 / 2010$ & 2,00 & - & 27,8 \\
\hline $\begin{array}{l}\text { Cassia angustifolia } \\
\text { (folhas) }\end{array}$ & Folhas, galhos e flores & - & - & 1,00 & - & 40,6 \\
\hline Peumus boldus (folhas) & Folhas e galhos & - & $07 / 20 / 2011$ & 1,00 & - & 20,4 \\
\hline $\begin{array}{c}\text { Baccharis trimera } \\
\text { (planta inteira) }\end{array}$ & Folhas, galhos e terra & - & $30 / 05 / 2011$ & 1,00 & - & 21,2 \\
\hline $\begin{array}{l}\text { Luffa operculata } \\
\text { (fruto) }\end{array}$ & Fruto seco com casca oxidada & - & - & 0,50 & - & 5,8 \\
\hline \multicolumn{7}{|c|}{ Grupo C } \\
\hline Hibiscus sabdariffa (flor) & $\begin{array}{c}\text { Flor de coloração vinho, } \\
\text { porém não totalmente } \\
\text { desidratada }\end{array}$ & - & - & 4,00 & - & 51,7 \\
\hline $\begin{array}{l}\text { Cassia angustifolia } \\
\text { (folhas) }\end{array}$ & $\begin{array}{c}\text { Folhas, flores amareladas e } \\
\text { material preto sólido }\end{array}$ & - & $26 / 09 / 2010$ & 1,50 & - & 50,2 \\
\hline Peumus boldus & $\begin{array}{l}\text { Folhas e galhos amarelados } \\
\text { de diferente pulverização }\end{array}$ & - & $25 / 06 / 2010$ & 2,00 & - & 51,2 \\
\hline $\begin{array}{c}\text { Baccharis trimera } \\
\text { (planta inteira) }\end{array}$ & $\begin{array}{c}\text { Folhas, galhos e material } \\
\text { pulverizado }\end{array}$ & - & $25 / 06 / 2010$ & 2,00 & - & 51,2 \\
\hline \multicolumn{7}{|c|}{ Grupo D } \\
\hline $\begin{array}{l}\text { Hibiscus sabdariffa } \\
\text { (flor) }\end{array}$ & Flor de coloração vinho & $12 / 2009$ & $10 / 11 / 2011$ & 2,50 & 30 & 29,5 \\
\hline $\begin{array}{c}\text { Cassia angustifolia } \\
\text { (folhas) }\end{array}$ & $\begin{array}{l}\text { Folhas amareladas e com } \\
\text { grande quantidade de flores }\end{array}$ & $02 / 2010$ & $09 / 11 / 2011$ & 2,00 & 30 & 29,0 \\
\hline Peumus boldus (folhas) & Folhas e galhos & $01 / 2010$ & $18 / 12 / 2011$ & 2,00 & 30 & 30,2 \\
\hline Baccharis trimera & Folhas e galhos & $03 / 2010$ & $16 / 02 / 2013$ & 2,00 & 30 & 30,3 \\
\hline Luffa operculata (fruto) & Fruto seco contendo casca & $02 / 2010$ & $25 / 08 / 2010$ & 3,00 & - & 6,4 \\
\hline
\end{tabular}

Rev. Bras. PI. Med., Campinas, v.15, n.4, supl.I, p.763-773, 2013. 
amostras. Provavelmente esta diferença se deva à presença de diferentes partes da planta (flor), ou coleta errônea de plantas, ou ainda a inserção de mistura de espécies por falta de um controle de qualidade a partir da empresa que a comercializa. Existe a predominância de constituintes polares em todas as amostras analisadas na fase móvel $\mathrm{CHCl}_{3} /$ $\mathrm{MeOH} / \mathrm{H}_{2} \mathrm{O}$ nas proporções 80:18:2, o que muito provavelmente está associado ao tipo de solvente empregado para a extração (etanol).

As análises das amostras de $C$. agustifolia, $B$. trimera e $H$. sabdariffa indicam a presença de diferentes tipos de constituintes fenólicos através da revelação da placa cromatográfica no UV e NP/PEG. As amostras de carqueja possuem flavonoides reveláveis em NP/PEG, no entanto, a amostra referente ao Grupo $C$ apresenta maior número de metabólitos pertencentes a esta classe de metabólitos, porém de Rfs diferentes das demais amostras. Através da análise do perfil químico destas diferentes plantas medicinais com propriedades abortivas reconhecidas na literatura, observa-se que não existe a predominância de única classe de metabólitos nas mesmas.

As análises dos chás destas plantas medicinais por CLAE indicaram a presença de derivados de ácidos fenólico e cafeoilquínico na amostra de $A$. vulgaris (Figura 1).

Em L. operculata os espectros de UV em $360 \mathrm{~nm}$ indicam a presença de derivados do ácido

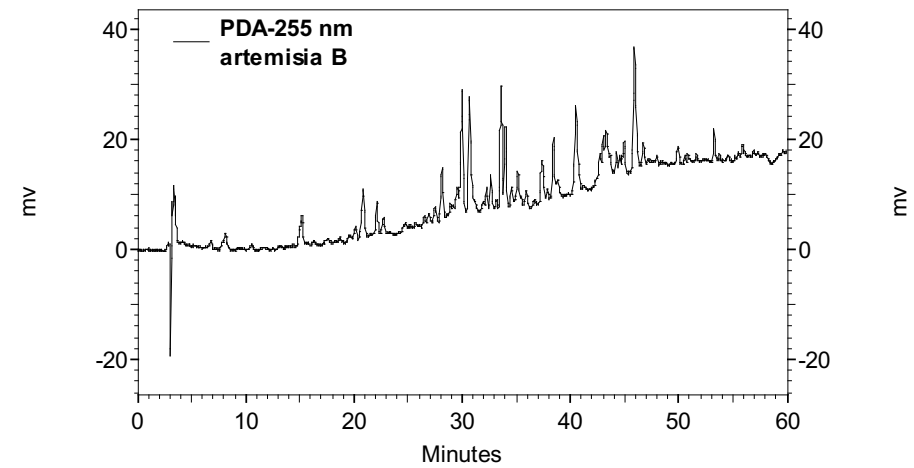

FIGURA 1. Análise por CLAE da amostra de Artemisia vulgaris. Detecção em $255 \mathrm{~nm}$.
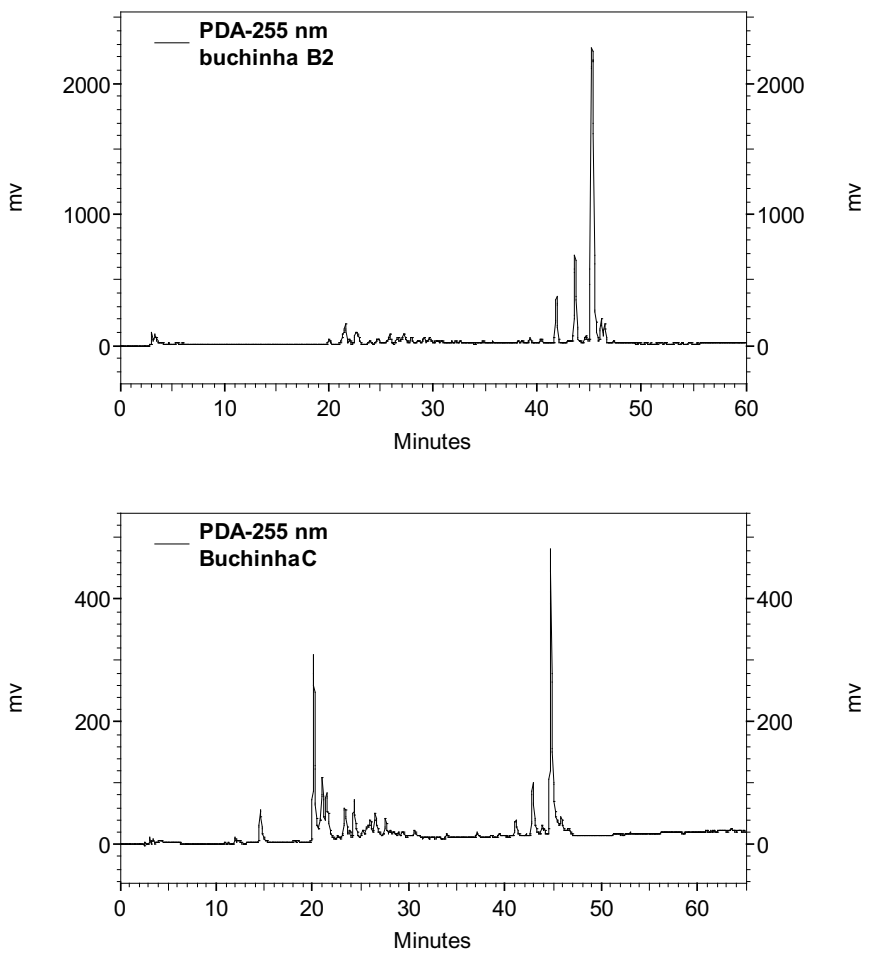

FIGURA 2. Análise por CLAE das amostras de L. operculata ("Buchinha do Norte"). Detecção em 255 nm.

Rev. Bras. PI. Med., Campinas, v.15, n.4, supl.I, p.763-773, 2013. 
cafeoilquínico e flavonoides (Figura 2). Já em $H$. sabdariffa, as análises por CLAE corroboram com aquelas observadas por CCD, amostras A e D são similares, enquanto $\mathbf{C}$ difere consideravelmente tanto na concentração quanto no número de constituintes presentes no extrato (Figura 3). Os dados sugerem a presença de antocianinas e derivados do ácido cafeoilquínico e fenólicos.

As análises dos chás destas plantas medicinais por CLAE indicaram a presença de derivados de ácidos fenólico e cafeoilquínico na amostra de $A$. vulgaris. Em L. operculata os espectros de UV em $360 \mathrm{~nm}$ indicam a presença de derivados do ácido cafeoilquínico e flavonóides. Já em $H$. sabdariffa os dados sugerem a presença de antocianinas e derivados do ácido cafeoilquínico e fenólicos.

As análises dos cromatogramas e bem como os espectros de UV das substâncias presenças nas amostras de $P$. boldus indicam taninos condensados e flavonóides. A injeção da boldina, alcalóide indicado pela literatura como sendo um marcador da espécie, mostrou a ausência da mesma em todas as amostras analisadas. Sugerindo que as amostras estudadas não se tratam de $P$. boldus, ou boldina pode não ser um bom marcador da espécie
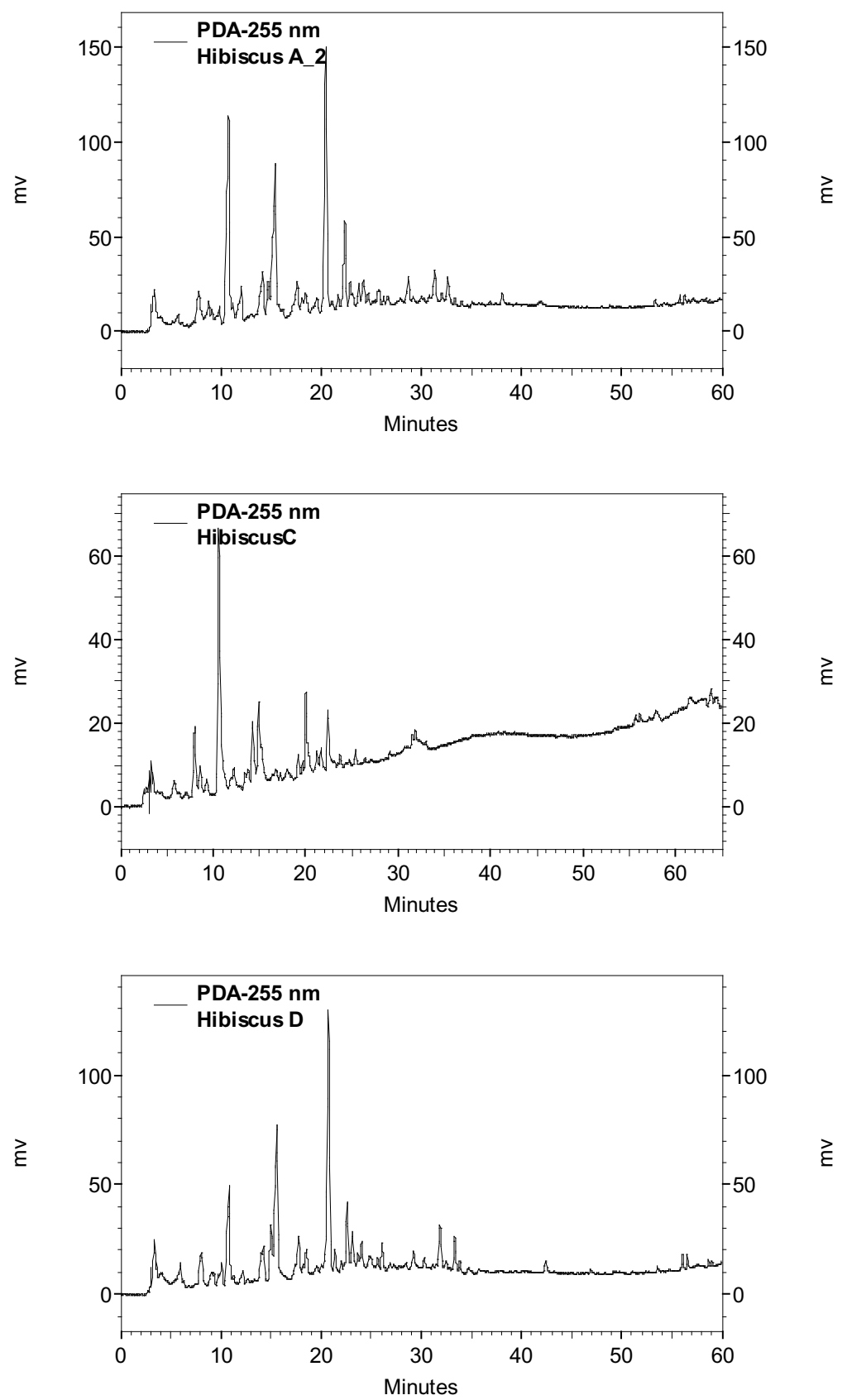

FIGURA 3. Análise por CLAE das amostras de H. sabdariffa. Detecção em 255 nm.

Rev. Bras. PI. Med., Campinas, v.15, n.4, supl.I, p.763-773, 2013. 
ou a mesma pode ter se degradado no processo de armazenagem ou extração (Figura 4).

Através das análises das amostras de C. angustifolia, os espectros de UV em $360 \mathrm{~nm}$ indicaram a presença de pelo menos 6 flavonóides diferentes eluindo na região de 25 a 43 min (Figura 5). Enquanto as amostras de $B$. trimera indicaram a presença de flavonóides eluindo nos primeiros 35 min, e derivados do ácido cafeoilquínico na região de 39 a 50 min (Figura 6).

De modo geral, as amostras de mesma espécie são similares no que diz respeito ao perfil químico, diferindo aparentemente na concentração dos constituintes presentes em cada amostra. Por outro lado, as duas amostras de $L$. operculata apresentam perfil químico significativamente diferente, apesar das análises por CCD terem indicado que as amostras eram similares exceto na eluição em $100 \%$ de $\mathrm{CHCl}_{3}$.

Através das análises das amostras de $C$. angustifolia, os espectros de UV em $360 \mathrm{~nm}$ indicam a presença de pelo menos 6 flavonóides diferentes identificados na região de 25 a 43 min. Enquanto as amostras de $B$. trimera fornece a presença de flavonóides identificados nos primeiros $35 \mathrm{~min}$, e derivados do ácido cafeoilquínico na região de 39 a $50 \mathrm{~min}$.

Todas as amostras pertencentes ao Grupo $C$, exceto $C$. angustifolia apresentaram assim como em CCD, um perfil químico bastante diferenciado das demais amostras, porém de forma muito mais proeminente, por se tratar de técnica mais sensível.

Como já constatado pela literatura, muitas plantas medicinais apresentam comprovação da atividade farmacológica pela qual a população as utiliza, porém, outras podem apresentar
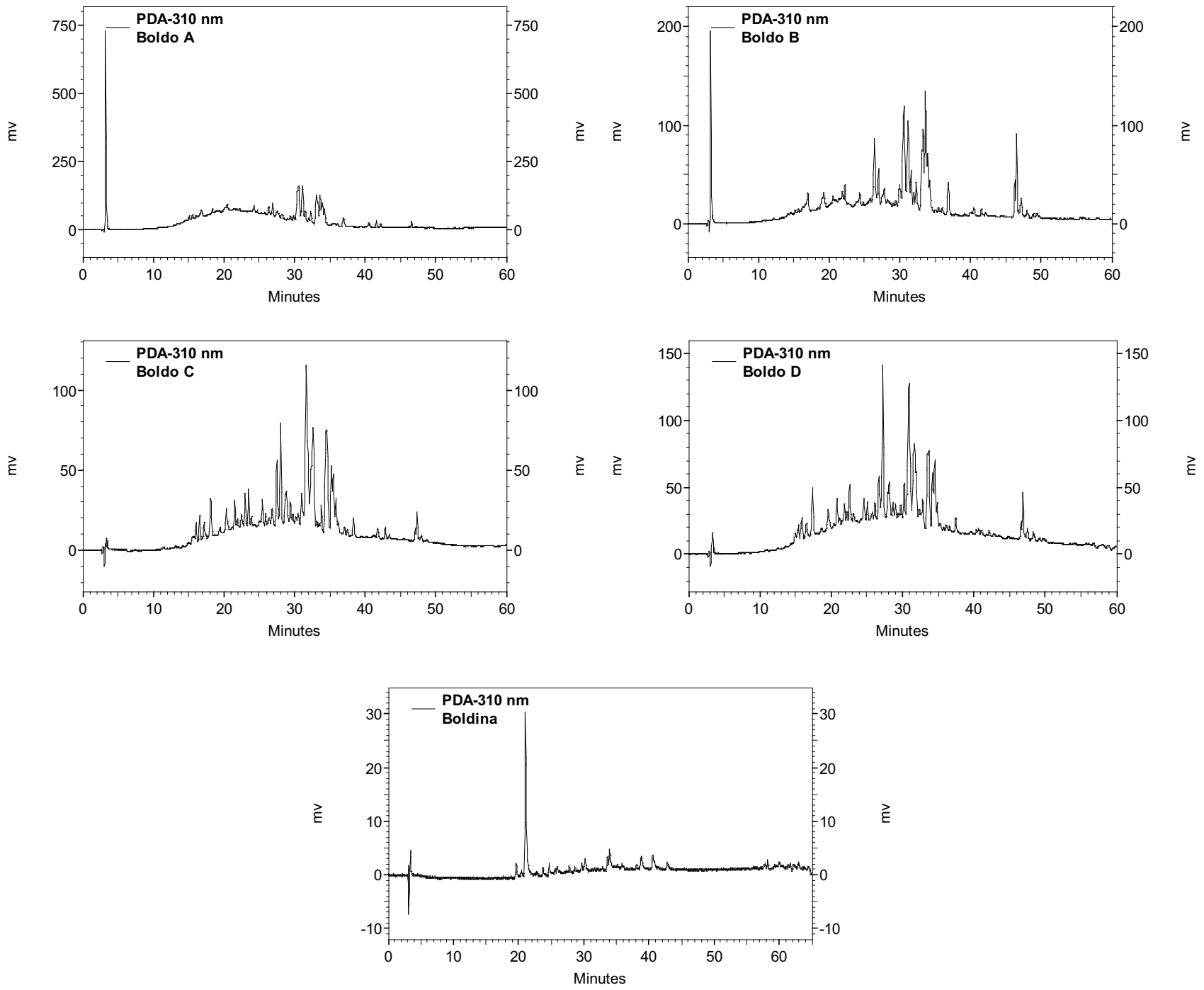

FIGURA 4. Análise por CLAE das amostras de P. boldus e boldina. Detecção em $255 \mathrm{~nm}$. 

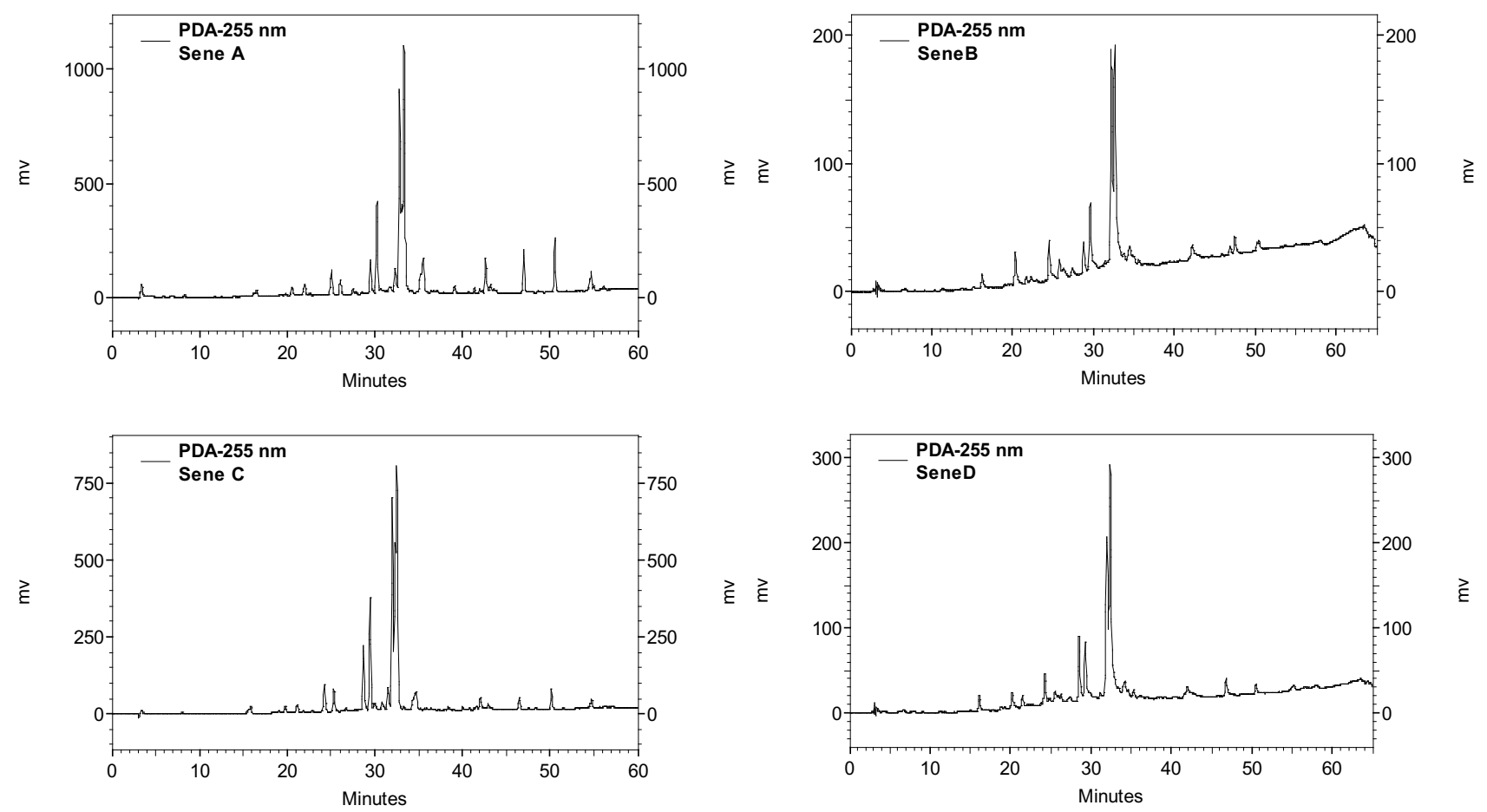

FIGURA 5. Análise por CLAE das amostras de C. angustifolia. Detecção em 255 nm.
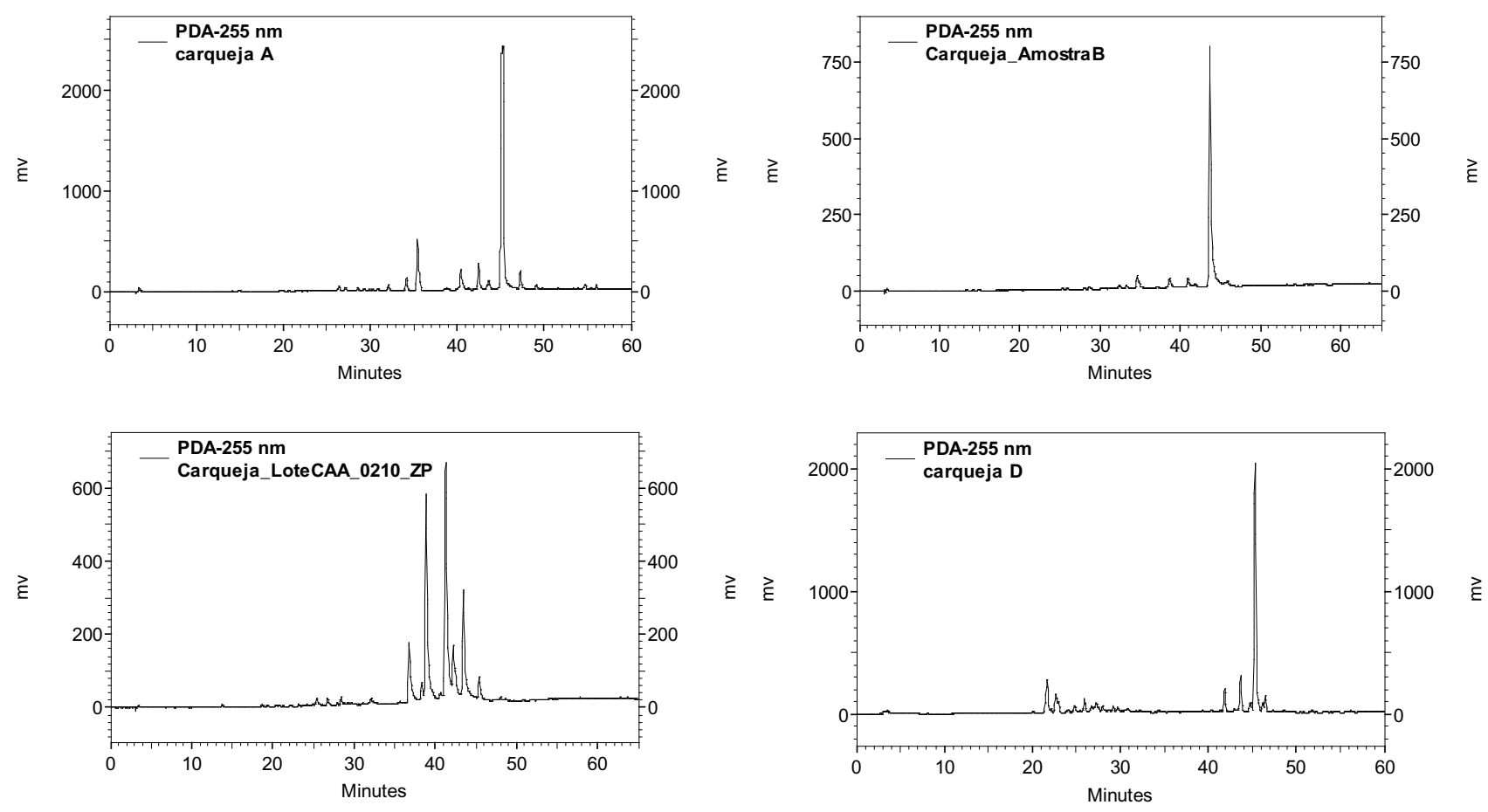

FIGURA 6. Análise por CLAE das amostras de B. trimera. Detecção em 255 nm.

Rev. Bras. PI. Med., Campinas, v.15, n.4, supl.I, p.763-773, 2013. 
concomitantemente propriedades abortivas, tóxicas e/ou mutagênicas não desejáveis. Como é o caso da boldina (alcalóide) e o P. boldus, os quais possuem atividades antioxidante, quimiopreventiva e antiinflamatória comprovadas (Gotteland et al., 1997; Kubinova et al., 2001; Quezada et al., 2004). No entanto, de acordo com Almeida (2000), o extrato hidroalcoólico de boldo e assim como a boldina apresentaram ações abortivas, teratogênicas em fêmeas de ratos. O extrato de sene (Senna alexandrina) possui propriedades laxativas confirmadas (Hancke et al., 2009).

No que diz respeito ao uso de carqueja (Baccharis trimera e $B$. genistelloides) para inúmeras finalidades, a literatura confirma o potencial antioxidante, anti-inflamatório, imunomodulatório e antiulcerogênico (Dias et al., 2009; Paul et al., 2009; Ares et al., 2010) em contrapartida, Ruiz et al. (2008) sugerem a proibição do chá de Baccharis genistelloides para gestantes devido ao efeito abortivo. No caso de $A$. vulgaris utilizada popularmente para regularizar o ciclo menstrual e cólicas, apresenta atividade antiespasmódica, broncodilatadora, hepatoprotetora, estrogênica, repelente e abortiva comprovadas (Lee et al., 1998; Gilani et al., 2005; Wang et al., 2006; Khan \& Gilani, 2009; Nácul et al., 2001). Dentre as espécies abordadas neste trabalho, $L$. operculata foi a única mencionada pelos lojistas como sendo de venda proibida no mercado, mas mesmo assim dois estabelecimentos forneceram amostras. A literatura relata as propriedades imunomodulatória, anti-HIV e antitumoral associadas aos extratos desta planta (NG et al., 1992a; NG et al., 1993b). A presença de curcubitacinas em sua composição química conferem propriedades embriotóxicas e abortivas, podendo levar até mesmo à morte (Matos, 2000). É sabido que mulheres em período gestacional sofrem frequentemente de enjoos e prisão de ventre, fazendo uso de medicamentos ou até mesmo de plantas medicinais como é o caso de boldo para minimizar a sensação indesejável de náuseas e carqueja para auxiliar nos incômodos ocasionados por disfunções gástricas comuns em períodos gravídicos. Neste sentido, um grande incentivo é requerido para subsidiar estudos envolvendo plantas medicinais para confirmação das atividades farmacológicas pelas quais as plantas são empregadas; avaliação de possíveis efeitos colaterais e também, um criterioso controle de qualidade.

\section{CONCLUSÃO}

As plantas medicinais mencionadas e estudadas neste trabalho, não apresentaram controle de qualidade e/ou normatização com relação às especificações nas embalagens, e separação do material vegetal a ser consumido. Fato confirmado através da análise do perfil químico das mesmas por cromatografia em camada delgada e por CLAE, exceto no que se refere às amostras $P$. boldus, cujas amostras apresentaram-se bastante similares.

\section{AGRADECIMENTO}

Ao CNPq pela concessão da bolsa de iniciação científica à aluna Nelly C. V. de SouzaMaria.

\section{REFERÊNCIA}

ALMEIDA, E.R. Toxicologial evalution of hydro-alcool extract of dry leaves of Peumus boldus and boldine in rats. Phytotherapy research, v.14, n.2, p.99-102, 2000.

ANESINI, C.; PEREZ, C. Screening of plants used in Argentine folk medicine for antimicrobial activity. Journal of Ethnopharmacology, v.39, n.2, p.119-28, 1993.

ARES, G.; BARREIRO, C.; GAMBARO, A. Evaluation of antioxidant extracts from Uruguayan native plants: importance of sensory characteristics. CYTA-Journal of Food, v.8, n.3, p.201-7, 2010.

BASU, K. Bharatiya Ousadhabalir Sankhipta Bhaisajya Tattwa. Calcutta: Hahnemann Publishing Company, 1946.

DIAS, L.F.D.; de MELO, E.S.; HERNANDES, L.S.; BACCHI, E.M. Antiulcerogenic and antioxidant activities of Baccharis trimera (Less) DC (Asteraceae). Revista Brasileira de Farmacognosia, v.19, n.1B, p.309-14, 2009.

DI STASI, L.C. Plantas medicinais: arte e ciência. Um guia de estudo interdisciplinar. São Paulo: Ed. UNESP, 1996. 230p.

FARNSWORTH, N.R.; AKERELE, O.; BINGEL, A.S.; SOERJATO, D.D.; GUO, Z. Medicinal plants in therapy. Bulletin of the World Health Organization, v.63, n.2, p.965-81, 1985.

FRIMPONG, C. Investigating the suitability of Hibiscus sabdariffa calyx extract as colouring agent for paediatric syrups. UNIVERSITY OF SCIENCE AND TECHNOLOGY, 2008, 121p.

GILANI, A.H.; YAEESH, S.; JAMAL, Q.; GHAYUR, M.N. Hepatoprotective activity of aqueous-methanol extract of Artemisia vulgaris. Phytotherapy Research, v.19, n.2, p.170-2, 2005.

GOTTELAND, M.; JIMENEZ, I.; BRUNSER, O.; ROMERO, S.; CASSELS, B.K.; SPEIKY, H. Protective effect of boldine in experimental colitis. Planta Medica, v.63, n.4, p.311-5, 1997.

$\mathrm{HAQ}$, I. Safety of medicinal plants. Pakistan Journal of Medical Research, v.43, n.4, p.203-10, 2004.

HANCKE, J.; CÁCERES, D.; BURGOS, R.A.; HERNÁNDEZ, D.; ROJAS, A.; MORALES, M.A. Acute and subchronic toxicological study of senna in rodents Boletin Latinoamericano y del Caribe de Plantas Medicinales y Aromaticas, v.8, n.2, p.67-76, 2009.

JOHNSON, A.E.; JAMES, L.F.; SPILLETT, J. Abortifacient 
and toxic effects of big sagebrush (Artemisia-tridentata) and juniper (Juniperus-osteosperma) on domestic sheep. Journal of Range Management, v.29, n.4, p.278-80, 1976 .

KHAN, A.U.; GILANI, A.H. Antispasmodic and bronchodilator activities of Artemisia vulgaris are mediated through dual blockade of muscarinic receptors and calcium influx. Journal of Ethnopharmacology, v.126, n.3, p.4806, 2009.

KUBINOVA, R.; MACHALA, M.; MINKSOVÁ, K.; NECA, J.; SUCHY, V. Chemoprotective activity of boldine: modulation of drug-metabolizing enzymes. Pharmazie, v.56, n.3, p.242-3, 2001.

LEE, S.J.; CHUNG, H-Y.; MAIER, C.G.A.; WOOD, A.R.; DIXON, R.A., MABRY, T.J. Estrogenic flavonoids from Artemisia vulgaris $\mathrm{L}$. Journal of Agricultural and Food Chemistry, v.46, n.8, p.3325-9, 1998.

MOREIRA, L.M.A.; DIAS, A.L.; RIBEIRO, H.B.S.; FALCÃO, C.L.; FELICIO, T.D.; STRINGUETTI, C.; SANTOS, M.D.F. Associação entre o uso de abortifacientes e defeitos congênitos. Revista Brasileira de Ginecologia e Obstetricia, v.23, n.8, p.517-21, 2001.

MENGUE, S.S.; SCHENKEL, E.P.; MENTZ, L.A.; SCHMIDT, L.I. Especies vegetales utilizadas por embarazadas con el objeto de provocar la menstruación (Encuesta a siete ciudades de Brasil). Acta Farmacéutica Bonaerense, v.16, n.2, p.251-8, 1997 (a).

MENGUE, S.S.; SCHENKEL, E.P.; DUNCAN, B.B.; SCHMIDT, M.I. Prevalence and clinical correlates of unsuccessfuluse of drugs to induce menstruation. Contracepction, v.57, n. 2, p.93-7, 1998 (b).

MATOS, F.J.A. Plantas medicinais: guia de seleção e emprego de plantas usadas em fitoterapia no nordeste do Brasil. $2^{\mathrm{a}}$ ed. Fortaleza: Editora UFC. 2000.

MONTANARI, T. ; BEVILACQUA, E. Effect of Maytenus ilicifolia Mart. on pregnant mice. Contraception, v.65, n.2, p.171-5, 2002.

NÁCUL, A.P.; CALLIARI-MARTIN, M.R.; CECHETTI, $D$. Uso de plantas medicinais com finalidade abortiva na periferia de Passo Fundo. In: MOSTRA DE INICIAÇÃO CIENTÍFICA DA UPF, 11., 2001, Passo Fundo. Resumo... Passo Fundo: UPF, 2001. p.55.

NG, T.B.; CHANG, W.Y.; YEUNG, H.W. Proteins with abortifacient, ribosome inactivating, immunomodulatory, antitumor and anti-AIDS activities from Cucurbitaceae plants. General Pharmacology, v.23, n.4, p.575-90, 1992(a).

NG, T.B.; CHAN, W.Y.; YEUNG, H.W. The ribosomeinactivating, antiproliferative and teratogenic activities and immunoreactivities of a protein from seeds of Luffa aegyptiaca (Cucurbitaceae). General Pharmacology, v.24, n.3, p.655-8, 1993(b).

OLIVEIRA, F. Q.; GONÇALVES L. A. Conhecimento sobre plantas medicinais e fitoterápicos e potencial de toxicidade por usuários de Belo Horizonte, Minas Gerais. Revista Eletrônica de Farmácia. v.3, n.2, p. 36-41, 2006.

PAUL, E.L.; LUNARDELLI, A.; CABERLON, E., de
OLIVEIRA, C.B.; SANTOS, R.C.; BIOLCHI, V.; BASTOS, C.M.; MOREIRA, K.B.; NUNES, F.B.; GOSMANN, G.; de OLIVEIRA, J.R. Anti-inflammatory and Immunomodulatory effects of Baccharis trimera aqueous extract on induced pleurisy in rats and lymphoproliferation in vitro. Inflammation, v.32, n.6, p.419-25, 2009.

PIATO, S.; TEDESCO, J.J.D.A. Diagnóstico e Terapêutica das Patologias Obstétricas. São Paulo: Editora Atheneu, 1984. 530p.

QUEZADA, N.; ASENCIO, M.; DEL VALLE, J.M.; AGUIRELLA, J.M.; GÓMEZ, B. Antioxidant activity of crude extract, alkaloid fraction, and flavonoid fraction from boldo (Peumus boldus Molina) leaves. Journal of Food Science, v.69, n.5, p.C371-6, 2004.

REIS, S.R.; MARIOT, A.; STEENBOK, W. Diversidade e domesticação de plantas medicinais. In: SIMÕES, C.M.O.; SCHENKEL, E.P.; GOSMANN, G.; MELLO, J.C.P.; MENTZ, L.A.; PETROVICK, P.R (orgs.). Farmacognosia: da planta ao medicamento. Porto Alegre/Florianópolis: Editora Universidade/ UFRGS e Ed. UFSC, 2002. 1102 p.

RODRIGUES, H.G; MEIRELES, C.G; LIMA, J.T.S; TOLEDO, G.P; CARDOSO, J.L; GOMES, S.L. Efeito embriotóxico, teratogênico e abortivo de plantas medicinais. Revista Brasileira de Plantas Medicinais, v.13, n.3, p.359-366, 2011.

RUIZ, A.L.T.G.; TAFFARELLO, D.; SOUZA, V.H.S.; CARVALHO, J.E. Farmacologia e Toxicologia de Peumus boldus e Baccharis genistelloides. Brazilian Journal of Pharmacognosy, v.18, n.2, p.295-300, 2008.

SANTOS, C.A. Aborto: um olhar displicente da sociedade. 1993. 76 f. Dissertação (Mestrado) - Universidade Federal de Minas Gerais, Belo Horizonte.

SILVA, J. N.; DANTAS, I. C. CHAVES, T.P. Plantas utilizadas como abortivas no município de Bom Jardim - PE. Revista de Biologia e Farmácia, v. 4, n.1, 2010.

SUTTISRI, R.; KINGHORN, A.D.; WRIGHT, A.D.; OTTO, $\mathrm{S}$. Neo-clerodane diterpenoids and other constituents from Baccharis genistelloides. Phytochemistry, v. 35, n.2, p.446-446, 1994

TEEB. A Quick Guide: The Economics of Ecosystems and Biodiversity for Local and Regional Policy, London: Earthscan, 2010.

VARANDA, E.A. Atividade mutagêncica de plantas medicinais. Revista de Ciências Farmacêuticas Básica e Aplicada, v. 27, n.1, p.1-7, 2006.

VEIGA JÚNIOR, V.F.; PINTO, A.C.; MACIEL, M.A.M. Plantas medicinais: cura segura? Química Nova, v.28, n.3, p.519-28, 2005.

WANG, J.; ZHU, F., ZHOU, X.M.; NYU, C.Y.; LEI, C.L. Repellent and fumigant activity of essential oil from Artemisia vulgaris to Tribolium castaneum (Herbst) (Coleoptera : Tenebrionidae). Journal of Stored Products Research, v.42, n.3, p.339-47, 2006.

WORLD HEALTH ORGANIZATION. Maternal Mortality 2000: estimates developed by WHO, UNICEF, UNFPA. Geneva: World Health Organization, 2003. 